meteorites. The result is a concise and factual account of lunar rocks written so as to be of value to a wide spectrum of scientists as well as students and laymen.

Following the introductory chapter on selenography prior to Apollo and a relatively short one on the Apollo programme, the authors give appreciablethough somewhat uncritical-attention chiefly to the mineralogy of Apollo 11 rocks. They note in particular the similarity with terrestrial basalts, but rightly draw attention to differences such as the absence of ferric iron and the presence of native iron and minerals such as troilite, armalcolite and pyrox-ferroite as indicative of the low partial pressure of oxygen during crystallization.

The next two chapters deal with lunar petrology, again with the chief emphasis on Apollo 11 rocks. Most important features of the igneous rocks, microbreccias and fines are ably described and some comparisons made with Apollo 12 samples. The controversial question of remanent magnetism and to what extent thermal remanent magnetism has been modified by later shock induced magnetism is discussed. The authors express hope, tinged with doubt, that oriented samples from bedrock exposures may solve the problem of the Moon's past magnetic field.

In the next chapter petrographic comparisons are made with terrestrial rocks, meteorites and tektites. The authors emphasize the similarities between lunar and terrestrial basalts as well as differences such as the presence of rare minerals not known on Earth. They are sceptical about the possibility of material getting into Earth-crossing orbit after being ejected by meteorites or comets striking the Moon. But, assuming that it could, they see no evidence of chondrites being derived from the Moon, though there is a better case for calcium-rich achondrites. Similarly, they see little evidence so far from lunar samples to indicate that tektites are of lunar origin with the possible exception of one Apollo 12 specimen.

The composition of lunar rocks is dealt with in an important chapter on lunar geochemistry (39 pages). Elemental abundances are given and compared with the diabase W-1 (which for many years has been used as a geochemical standard), eucrites, and carbonaceous chrondrites. Here the authors' critical judgment is particularly effective and the result is not only an excellent tabular display of data, but a discussion, element by element, of the analytical methods of determination and of the significance of different elemental concentrations. Particular attention is given to patterns of elemental enrichment and depletion as compared with terrestrial rocks, meteorites and possible cosmic abundances.

The final chapter considers the implications for lunar history of the most significant facts so far established by the Apollo missions. It deals with the origin of the maria and other surface features, with the internal structure of the Moon and the nature of the mascons, and with the four principal hypotheses currently in vogue for the origin of the Moon. Of these, favour is given to the Öpik-Ringwood hypothesis which, briefly, suggests that the Moon was formed as a result of the coalescence of a ring of planetesimals that once surrounded the Earth following the disruption and subsequent cooling of a massive primitive atmosphere.

The book has a list of about 150 selected references and an author/subject index. It is well printed and illustrated and suffers little from being produced in a relatively short period of time. It is highly recommended to all interested in lunar rocks and in what the authors describe as having been "a unique scientific adventure, and an intellectual challenge of the first magnitude" to many scientists of different disciplines. S. H. U. BowIE

\section{Ordering and Stacking}

Ordered Alloys: Structural Applications and Physical Metallurgy. Edited by Bernard H. Kear, Chester T. Sims, Norman S. Stoloff and Jack H. Westbrook. (Third Bolton Landing Conference, Lake George, New York, September 1969.) Pp. 580. (Claitor: Baton Rouge, 1970.)

IT is unfortunate that the proceedings of this conference have taken so long to be published. The field covered continues to be an active area of research and certainly parts of this book are now somewhat dated. Also, as invariably happens, many of the papers contain material which was published elsewhere before the conference, or has since been published in a revised form. These criticisms apart, there is no doubt that this well produced and very well edited book will become a standard reference for research workers in the field. It may well also prove useful to advanced undergraduate students in materials science and related fields who need a source of critical articles for a project involving a literature survey in this general area.

The conference attempted to cover an extremely wide field, from the theory of order/disorder transformations to the engineering applications of materials containing ordered precipitate particles. The articles in the proceedings again have this same scope and it might have been expected that the volume would seem disjointed and the individual papers unrelated. All in all, this has not happened; the editors are to be congratulated on subsectioning the proceedings into well related groups of papers and a sometimes tenuous thread between the sections has been main- tained. This thread is much easier to follow thanks to an excellent initial review by one of the editors (J. H. Westbrook) which gives an admirably brief survey of the whole field.

After this initial review, the first section consists of a series of papers on the theory of order and phase stability. These papers chiefly consider relatively conventional models of ordering, but there is a clear contribution in the attempts that have been made to refine the various models and present more quantitative interpretations of the property changes on ordering. The next section has papers on stacking and stacking faults. Many of the ideas presented here are taken up again in the papers more concerned with applications in the latter parts of the proceedings. The following section considers the mechanism and kinetics of ordering; much of the material here is the relatively conventional interpretation of kinetic experiments, but the simulation studies by Beeler using a computer indicate a relatively new departure. The next two sections cover the mechanical properties of, first, single phase intermetallics, and then multiphase alloys. A considerable number of these papers make important contributions to the theory of hardening due to the presence of ordered particles. The final section deals with engineering applications, covering fracture creep, fatigue and so on.

The continuing interest in this area suggests that it would be useful to have a repeat of this type of conference every few years.

B. RALPH

\section{Plants and Parasites}

Physiological Plant Pathology: An International Journal of Experimental Plant Pathology. Edited by T. F. Preece and B. J. Deverall. (Published quarterly by Academic: London and New York, 1971.) £7.00 annually.

INTEREST in the relationship between plant hosts and their parasites has increased greatly since 1920 when Professor W. Brown, FRS, began his distinguished researches on this subject at the Imperial College of Science and Technology, London. The new specialized journal, Physiological Plant Pathology, offers an outlet for papers on all aspects of the plant host/parasite relationship and can be expected to bring together much of the work which would otherwise be scattered in a number of more or less suitable journals.

The editors have wisely laid down fairly precise limits on the subject matter to be included in the new journal. Nevertheless the first number shows that they have not interpreted their ruling in any narrow sense but have accepted papers ranging 